BMJ Open

Sport \&

Exercise

Medicine

\section{Spotlight on the fetus: how physical activity during pregnancy influences fetal health: a narrative review}

To cite: Bauer I, Hartkopf J, Kullmann S, et al. Spotlight on the fetus: how physical activity during pregnancy influences fetal health: a narrative review. BMJ Open Sport \& Exercise Medicine 2020;6:e000658. doi:10.1136/ bmjsem-2019-000658

- Additional material is published online only. To view please visit the journal online (http://dx.doi.org/10.1136/ bmjsem-2019-000658).

Accepted 17 February 2020

Check for updates

C) Author(s) (or their employer(s)) 2020. Re-use permitted under CC BY-NC. No commercial re-use. See rights and permissions. Published by BMJ.

For numbered affiliations see end of article.

Correspondence to

Ilena Bauer;

ilena.bauer@uni-tuebingen.de

\section{ABSTRACT}

Before and during pregnancy, women often aim to improve their lifestyle so as to provide a healthier environment for their developing child. It remains unresolved, however, as to whether physical activity (PA) during pregnancy poses a possible risk or whether it might even have beneficial effects on the developing child. There is increasing evidence that PA during pregnancy is indeed beneficial to maternal physiological and psychological health and that it is generally not detrimental to the fetal cardiovascular system and neuronal function in the developing child. This also led to international recommendations for PAs during pregnancy. In the current review, we aimed to comprehensively assess the evidence of beneficial and harmful effects of maternal PA, including highperformance sports, on fetal development. The different mental and body-based relaxation techniques presented here are frequently performed during pregnancy. We found a considerable number of studies addressing these issues. In general, neither low key, moderate maternal PA nor relaxation techniques were observed to have a harmful effect on the developing child. However, we identified some forms of PA which could have at least a transient unfavourable effect. Notably, the literature currently available does not provide enough evidence to enable us to make a general conclusive statement on this subject. This is due to the lack of longitudinal studies on the metabolic and cognitive effects of regular PA during pregnancy and the wide diversity of methods used. In particular, the kind of PA investigated in each study differed from study to study.

\section{INTRODUCTION}

In pregnancy, women are affected by a number of physiological and psychological alterations. Physiological adaptations include musculoskeletal, hormonal and cardiovascular changes (change in their centre of gravity, weight gain, fluid increase, increase of heart rate (HR), increase in plasma volume, etc). ${ }^{1}$ In addition, pregnancy is often associated with changes in mood and emotional states. $^{2-4}$ In addition, a number of pregnant women reported that they did not have

\section{What is already known?}

During an uncomplicated pregnancy, physical activity with low intensity does not harm the fetus.

\section{What are the new findings?}

Current evidence related to physical activity and fetal development is still limited.

- Only transient beneficial effects are shown but negative effects cannot be ruled out.

Effects depend on the intensity and duration of physical activity.

specific knowledge of adequate activities during pregnancy. ${ }^{5}$

In 2017, the American College of Obstetricians and Gynecologists (ACOG) recommended that pregnant women partake in regular physical activity (PA) during pregnancy by engaging in at least $150 \mathrm{~min}$ of moderate-intensity aerobic on a weekly basis. However, it was acknowledged that 'some modifications to exercise routines may be necessary because of normal anatomic and physiological changes and fetal requirements' ${ }^{6}$ Following evaluation by their obstetric care providers or obstetrician-gynaecologists, women with uncomplicated pregnancies can engage in aerobic and strength-conditioning exercises during pregnancy. In 2019, yoga and/or gentle stretching was recommended on the basis of Canadian guidelines. ${ }^{7}$ With regard to the postpartum period, it might be beneficial to gradually build up the intensity levels, that is, from moderate to vigorous, depending on the women's state of health. However, the ACOG recognises the need for additional research with regard to pregnancyspecific outcomes and the optimal frequency and intensity 'to create an improved evidence base concerning the effects of occupational physical activity on maternal-fetal health'. 
Due to its important role in maintaining a healthy lifestyle, PA has received more attention over the past few decades. Furthermore, the worldwide increase in obesity ${ }^{10}$ poses a tremendous challenge in obstetrics. Obese women have a higher risk of developing gestational diabetes and an increased risk of excessive gestational weight gain ${ }^{11}$ with possible negative outcomes for both mother and child in later life. ${ }^{12} 13$ PA during pregnancy not only lessens the risk of gestational diabetes by reducing maternal blood glucose, ${ }^{14}$ pre-eclampsia ${ }^{15}$ and pregnancy-induced hypertension but also lowers the risk for caesarean section ${ }^{16-19}$ and the severity of prenatal depressive symptoms. ${ }^{20}$

\section{Fetal programming: a historical perspective}

In 1990, Barker and colleagues first coined the term 'fetal programming' to exemplify the pivotal role of the intrauterine environment on disease risk in later life. Specifically, they showed a link between low birth weight and the risk of developing type 2 diabetes later in life, describing this process as an imprinting span for the risk of diseases in adulthood. ${ }^{21}$ This process of fetal programming includes maternal body composition, maternal dietary intake, uteroplacental blood flow, placental transfer and fetal genome, which can then lead to metabolic and endocrine changes in the fetus. ${ }^{22}$ Over the past few decades, this concept has been further developed as developmental origins of health and diseases (DOHaD). With a special focus on fetal development, it provides a theoretical framework for improving human well-being with a special focus on fetal development. Meanwhile, however, the less deterministic term conditioning is preferred to that of programming because ' $[\ldots]$ it does not carry the implication that disease processes start during development [...]'.[ ${ }^{23}$ p.1060] The DOHaD concept refers to early life and later risk of disease and does not underpin the 'predetermined ballistic course of development and later function rather than plasticity'. $\left[{ }^{23}\right.$ p.1028] Instead, it marks a 'turning point' with regard to the prevention of diseases at an early stage of life. This may confirm the importance of prepregnancy interventions/ conditions, including PA and interventions/conditions during pregnancy.

\section{How to assess fetal well-being: methods and approaches}

Different approaches and methods are available for the assessment of fetal well-being. ${ }^{24}$ Cardiotocographic (CTG) monitoring and the umbilical artery Doppler are the most common methods applied in gynaecological care. CTG is used to register the fetal heart rate (fHR) and uterine contractions at the same time. The fHR is judged by baseline, oscillation and variation by the common Fédération Internationale de Gynécologie et d'Obstétrique (FIGO) score. Nowadays, computer-enhanced CTG (Oxford-CTG) is also available. ${ }^{25}$ The overall aim is to determine whether the fetus is suffering from a lack of oxygen or whether it is in a state of emergency, such as an acidosis, and requires, for example, caesarean section delivery. ${ }^{26}$ The umbilical artery Doppler is mainly used to assess the blood flow between fetus and placenta, and shows the resistance in the end-diastolic flow. It is a wellestablished method for the surveillance of fetuses with growth restriction. It also helps medical stuff to decide when a baby should be delivered, beginning with the screening of uterine blood flow in the second trimester. It is then possible to foresee hypertensive complications throughout later pregnancy by scanning the uterine arteries on both sides. ${ }^{27}$ In several cases the Doppler ultrasound can be used to study fetal circulatory systems such as the umbilical artery and the medial cerebral artery by using the cerebral-placental-uterine ratio to observe fetal centralisation. In centralisation the fetus saves its resources for important areas like the brain. At this stage, there is no further relevant growth; the fetus simply matures. In some studies, the biophysical profile (BPP) by Manning ${ }^{28}$ was used to determine fetal well-being. BPP combines two methods, CTG and ultrasound using five components: fHR, fetal movements and breathing, fetal tone and amniotic fluid volume. However, BPP is known to be an inadequate means of determining fetal wellbeing in high-risk pregnancies. ${ }^{29}$ Another indication for measuring the middle cerebral artery (MCA) Doppler is to detect fetal anaemia, that is, in Parvovirus-B19infections or Rhesus disease. Since the maximum velocity of the MCA is related to the percentage of blood cells in the fetal blood, an anaemic child has a higher velocity in the MCA.

The Ductus venosus (DV) Doppler is a method which connects the intra-abdominal portion of the umbilical vein to the left portion of the vena cava below the diaphragm, and its outcome measure is the blood flow between these areas. $^{30}$ The cerebral-placental-uterine ratio is a method with which the blood flow in maternal, fetal and placental vessels can be measured to predict any growth restriction in the fetus. ${ }^{31}$

More recently, direct physiological measurements of electrical and magnetic heart activity have become available. Electrical measurements are limited in the last trimester of pregnancy, whereas biomagnetic recordings can be used to record fetal heart activity, fetal breathing activity and fetal brain activity, particularly during the third trimester. On the basis of high temporal resolution, the HR and heart rate variability (HRV) measurements can be determined to assess the status of the fetal autonomic nervous system (ANS). This non-invasive technology is used to investigate the fetal neurophysiology. ${ }^{32}$ In addition, fetal magnetoencephalography enables us to investigate functional fetal brain development. Alternatively, MRI and functional MRI can be used for fetal neuronal assessment. ${ }^{33}$

Physical activity during pregnancy: current status of research Over the past few years, a number of studies investigated the effects of PA on fetal well-being. ${ }^{34-36}$ In particular, the risk of preterm birth is one of great concern. The theoretical basis for the concern of preterm delivery 
is based on two possible interacting factors: (1) the increase in catecholamines, which could subsequently stimulate myometrial activity and (2) the decrease in oxidative stress, which can improve placenta vascularisation, thereby preventing preterm birth. ${ }^{36}$ In a recent meta-analysis, DiMascio and colleagues ${ }^{37}$ reported no association between maternal exercise and preterm birth in normal-weight women with uncomplicated, singleton pregnancies. In addition, a recent meta-analysis ${ }^{38}$ showed that prenatal exercise did not lead to an increase in birth complications or changes in developmental outcome. With regard to female elite athletes, the elite level was not shown to be associated with higher rates of emergency caesarean deliveries or prolonged second stages of labour. $^{39}$

In a large-scale population-based study ( $\mathrm{n}=92796)$, Takami et al reported that prepregnancy PA had no effect on adverse birth outcomes related to preterm birth and caesarean delivery. However, low level of PA during pregnancy (less than 30 min moderate PA per day) increased the risk of preterm birth in comparison to moderate PA. One limiting factor of the study was that PA was assessed by questionnaires only.

These studies indicate that PA can be safely performed during pregnancy in uncomplicated pregnancies without a significantly higher risk of preterm birth (PA extent: 35-40 min, 3-4 times per week during pregnancy).

Important parameters for fetal well-being are fetal breathing $^{40}$ which can provide information about the development of the fetal respiratory system and fetal body movements which can be taken as an indicator of the fetal maturation of the central nervous system. ${ }^{41}$ A review by Sussman $e t a l^{35}$ suggested that vigorous maternal exercise can have a slight impact on fetal breathing and body movements with mainly ambiguous results. It is therefore not possible to draw any conclusions about any effects. With regard to the autonomic nervous system (ANS), an article by May et $a l^{34}$ showed that aerobic exercise or resistance exercise had no adverse influence on the cardiovascular activity of the fetus.

Our review focuses explicitly on fetal health in relation to maternal prenatal PA under various concrete aspects. The term PA is hereby used as a hypernym for any physical movement such as gardening, walking or housekeeping and sports activities. The term maternal exercise specifically addresses any supervised or unsupervised exercise training only and is a subtype of PA.

Furthermore, for the first time, this review extends its scope to include maternal competitive sports as well as relaxation techniques during pregnancy as further factors that might influence fetal development. Since there are two optional ways of performing relaxation techniques (mental/body-based), this category can be clearly classified under PA and should not be disregarded.

\section{Study selection and data extraction}

Between May 2017 and October 2019, we searched the following databases: Pubmed, Web of Science and Surf
Table 1 Search query 1: fetal responses to maternal exercise

\begin{tabular}{ll}
\hline Databases & Keywords \\
\hline Pubmed & $\begin{array}{l}\text { Physical activity OR maternal exercise AND } \\
\text { fetal nervous system }\end{array}$ \\
Web of Science & $\begin{array}{l}\text { Physical activity in pregnancy and fetal } \\
\text { brain development }\end{array}$ \\
Surf & Physical activity in pregnancy \\
\hline
\end{tabular}

To summarise studies involving 'Fetal responses to maternal exercise' a first search with terms 'physical activity OR maternal exercise AND fetal nervous system' in Pubmed was carried out. For the second search in database Web of Science, we used terms 'physical activity in pregnancy and fetal brain development'. Finally, we used the keywords 'physical activity in pregnancy' for database search in Surf.

(Bisp) as data sources (for overview see online supplementary table 1)

The population of interest was comprised of healthy singleton pregnant women with an uncomplicated pregnancy.

We began by screening the titles and abstracts of all retrieved articles. For each search query (see table 1 and table 2), we included only those publications which fulfilled the inclusion criteria and excluded any duplicates. Reference sections of studies which fulfilled inclusion criteria were also screened for further potentially relevant articles.

Each article was examined for eligibility by setting the following inclusion criteria:

1. Studies resulting from the first search were screened for the following inclusion criteria:

- Previously sedentary or active subjects or athletes.

- Language: German or English.

- Healthy subjects and healthy control groups.

- Original research articles.

- All types of physical activities.

- >18 years old.

- Singleton pregnancies.

- Outcome: fetus.

2. Studies resulting from the second query were screened for the same inclusion criteria but 'all types of physical activity' was replaced by 'all types of relaxation'.

Table 2 Search query 2: relaxation techniques in pregnancy and their effects on fetal development

\begin{tabular}{ll}
\hline Databases & Keywords \\
\hline Pubmed & $\begin{array}{l}\text { Yoga OR relaxation techniques AND } \\
\text { pregnancy AND fetus }\end{array}$ \\
Web of Science & Relaxation in pregnancy AND fetus
\end{tabular}

We conducted a second run with the terms 'Yoga OR relaxation techniques AND pregnancy AND fetus' to screen for 'relaxation techniques in pregnancy and its effects on fetal development' in Pubmed database. For the study selection in Web of Science, we used the term 'Relaxation in pregnancy AND fetus'. 
Table 3 Definitions of exercise levels

\begin{tabular}{llll}
\hline Non-active/sedentary & Active & Highly active & Elite athletes \\
\hline Mainly sedentary women who & Active women who reported & Highly active women who & Women who trained multiple \\
did not explicitly exercise at all & $\begin{array}{l}\text { regularly exercising at a } \\
\text { moderate to vigorous level }\end{array}$ & $\begin{array}{l}\text { exersed multiple times } \\
\text { during the week at a moderate level for competitive reasons } \\
\text { to strenuous level }\end{array}$ \\
\hline
\end{tabular}

The results together with the limitations and perspectives of exemplary studies are summarised and discussed in the following sections. Table 3 clearly defines the different exercise levels described in the studies.

\section{EFFECTS OF PA ON FETAL AUTONOMIC NERVOUS SYSTEM}

One well-established method of measuring fetal wellbeing during maternal exercise is to observe the fHR and fetal heart rate variability (fHRV), both of which are indicators for a healthy and well-balanced or, indeed, for a poorly developed fetal ANS. ${ }^{42-44}$ The ANS is composed of parasympathetic and sympathetic components which are quick to respond and adapt to their environment. ${ }^{45}$ The parameters described in most of the studies are summarised in table 4 .
Several other studies focused on determining whether PA has any adverse effects for fetal well-being by employing parameters of the ANS. Specifically, '[...] exercise during pregnancy lowers heart rate (HR) and can attenuate the symptoms of gestational conditions associated with increased sympathetic control $[\ldots]^{46}$ p.611] over time. ${ }^{47}$ An increased HR and a decreased variability were shown to be associated with hypertension. ${ }^{48}{ }^{49}$ In this context, fetal breathing and fetal movement are connected to the fetal ANS in different ways. This may indicate a consistent index of fetal overall health. ${ }^{50}$ They also correlate with fetal activity states. ${ }^{51}$ The non-active state was defined by absent or shortlived HR acceleration. The active state was defined by frequent and long-lasting HR acceleration. ${ }^{52}$

Table 4 Overview of parameters associated with fetal ANS

\begin{tabular}{|c|c|c|c|c|c|}
\hline Methods & Parameters & Description & $\begin{array}{l}\text { Associated } \\
\text { autonomic function }\end{array}$ & $\begin{array}{l}\text { Over the course } \\
\text { of pregnancy }\end{array}$ & Interpretation \\
\hline \multirow[t]{2}{*}{$\begin{array}{l}\text { Doppler } \\
\text { ultrasound, CTG, } \\
\text { dMMG (marker), } \\
\text { fMCG, BPP }\end{array}$} & $f H R$ & Fetal heart rate & $\begin{array}{l}\text { Sympathetic and } \\
\text { parasympathetic } \\
\text { activity }\end{array}$ & $\begin{array}{l}\text { Decreases } \\
\text { slightly over } \\
\mathrm{GA}^{115116} \\
\text { (normal range: } \\
110-150 \text { beats/ } \\
\text { min) }\end{array}$ & $\begin{array}{l}\text { Pathological } \\
\text { fHR: }<100 \text { beats/min or } \\
>170 \text { beats } / \mathrm{min} \text { with a } \\
\text { bandwidth of }<5 \text { and } \\
\geq 90 \text { min } \rightarrow \text { indicates an } \\
\text { insufficient fetal oxygen } \\
\text { supply }\end{array}$ \\
\hline & $f H R V$ & $\begin{array}{l}\text { Fetal heart rate } \\
\text { variability }\end{array}$ & $\begin{array}{l}\text { Sympathetic and } \\
\text { parasympathetic } \\
\text { activity (sympatho- } \\
\text { vagal balance) }\end{array}$ & $\begin{array}{l}\text { Increases with } \\
\mathrm{GA}^{42118}\end{array}$ & $\begin{array}{l}\text { An increase is } \\
\text { associated with vagal } \\
\text { and sympathetic } \\
\text { activity which may be } \\
\text { associated with the } \\
\text { ability to respond to } \\
\text { regulatory mechanisms } \\
119120\end{array}$ \\
\hline $\begin{array}{l}\text { Doppler } \\
\text { ultrasound, CTG, } \\
\text { dMMG (marker), } \\
\text { fMCG, BPP }\end{array}$ & $\begin{array}{l}\text { Fetal body } \\
\text { movements }\end{array}$ & $\begin{array}{l}\text { Can be indirectly } \\
\text { detected through } \\
\text { fMCG beginning at } \\
18 \mathrm{GA}^{41}\end{array}$ & $\mathrm{fHR}$ & $\begin{array}{l}\text { Increases over } \\
\text { the course of } \\
\text { pregnancy } \\
124\end{array}$ & $\begin{array}{l}\text { A reduction in fetal } \\
\text { movements is } \\
\text { associated with adverse } \\
\text { pregnancy outcomes in } \\
\text { pregnancy }{ }^{124}\end{array}$ \\
\hline
\end{tabular}

ANS, autonomic nervous system; BPP, biophysical profile; CTG, cardiotocography; dMMG, diaphragmatic magnetomyogram ; fHR, fetal heart rate; fHRV, fetal heart rate variability; fMCG, fetal magnetocardiography; GA, gestational age; HRV, heart rate variability. 
Fetal breathing is not continuous during development and apnea periods also occur. Gustafson et a $\tilde{l}^{\tilde{3}}$ investigated the effect of breathing and maternal exercise on fHR and fHRV. They measured women at 36 weeks of GA, using ultrasound to determine fetal movement and fetal biomagnetometer to assess fetal breathing and fetal cardiovascular activity. Subjects were assigned to the exercise or control group on the basis of their previously reported PA record in the Modifiable Physical Activity Questionnaire (MPAQ). Women in the control group were below the minimum amount of the ACOG recommendations. Both exercise and breathing led to decreased fHR and increased fHRV. Interestingly, a correlation between maternal exercise and fetal breathing was observed, indicating that the effect of exercise was found during breathing only. The reported increase in fHRV during maternal exercise indicates an improved fetal regulatory mechanism with regard to the maternal environment. ${ }^{48}$

Only a few studies investigated the effects of resistance exercise, reporting no adverse effects on fetal ANS. ${ }^{54}$ In detail, Bgeginski et $a l^{54}$ investigated resistance exercise in 10 pregnant women who had not participated in resistance exercises 3 months prior to the study. At the three measurement time points from a total of 12 visits (four visits at each gestational age period: 22-24, 28-32 and 34-36 weeks), the fHR did not differ significantly.

A similar result was reported in a study by Avery $e t$ $a \tilde{l}^{55}$ who investigated the fetal cardiovascular responses to maternal strength conditioning exercises in late gestation. Measurements were taken during the third trimester of gestation, when the 12 women performed different resistance exercises in the supine and seated position. Significantly higher accelerations in fHR during resistance exercise in the supine position were observed. In addition, a transient mild bradycardia was occasionally observed $(<3 \mathrm{~min})$. This mild bradycardia may be a response to the blood flow redistribution before and after the exercises due to the changes in posture (supine/ sitting). This is in line with another study ${ }^{56}$ in which fHR was measured continuously during static exercise over 4-8 visits during pregnancy. The total procedure lasted 35-40 min, including a previous and subsequent baseline measurement, each lasting 10 minutes. Abnormal CTG patterns were reported in only a small number of women who performed static exercises in the supine position in late pregnancy. This indicates that there are possible adverse effects for the fetus with regard to exercise in supine position. A systematic review by Mottola et $a \tilde{l}^{7}$ recently shed some light on the question as to whether resistance exercise in the supine position actually harms the fetus. 'Low' quality evidence from observational studies suggested that there were no effects. Notably, $31 \%$ of the fetuses showed at least one potential adverse event during resistance exercise in the supine position (reduced fHRV and reactivity, variable fHR decelerations or fetal bradycardia). ${ }^{57}$ On the basis of this research, there is a considerable amount of evidence to suggest that resistance exercise in a supine position during pregnancy is not beneficial to the fetus.

On the basis of our current knowledge, pregnant women should therefore avoid resistance exercise in the supine position since no benefit for the fetus has been observed and because harm cannot be categorically ruled out.

The effect of different types of sports on the fetal ANS, including swimming, aerobic exercise and cycling, was also investigated during the last decades. Silveira et al studied the effect of moderate-intensity supervised water aerobics on fetal cardiovascular activity. Indeed, between 24 and 27 weeks of gestation, fHRV increased following aerobic exercise. ${ }^{58}$ An increase in fetal body movement, which varied from $34 \%$ to $7 \%-17 \%$ over the same period, was also observed. This increase in fetal body movement may be associated with a normal physiological response of the fetus. The increase in fHRV indicates an increase in sympathetic activity and may constitute a normal response of the fetus.

In their intervention study, McMurray et a $\bar{l}^{59}$ investigated subjects between 21 and 29 weeks of GA who performed aerobic and treadmill walking as a control condition. Real-time ultrasound was used for fHR and variability, ECG for maternal $\mathrm{HR}$, and variability and gas meter for expired gases which were analysed with respect to the oxygen and carbon dioxide concentrations of the mother. In the second trimester, a significantly higher fHR was observed after the aerobic exercise than after walking on a treadmill in the second trimester. The higher fHR during aerobic can be defined as mild tachycardia and interpreted as a normal physiological response to maternal exercise. A recent pilot study $(n=88)$ with no control group reported lower mean fetal movements and a transient bradycardia in the exercise phase (phases: baseline, exercise, recovery period) during moderateintensity walking (three times per week for $15 \mathrm{~min}$ ) in pregnant women at 36 weeks of GA ${ }^{60}$ Notably, the mean fHR in obese/overweight women was lower than in normal/low weight pregnant women. With regard to the transient bradycardia, the scientists reported an association with the maternal weight/maternal fitness level. The bradycardia reported may not have been primarily caused by maternal exercise and may have no clinical implications. Further research is, however, required on this subject.

A retrospective study ${ }^{61}$ differentiated between continuous and non-continuous exercise. Continuous PAs included, for example, jogging, walking or swimming. Non-continuous PAs included moderate aerobic and/or anaerobic intervals $\left[{ }^{61}\right.$ p.366] such as resistance training or yoga. In this retrospective analysis of a cross-sectional study, fetal biomagnetometer was used to assess fetal and maternal HR. The expectant mothers were requested to use the MPAQ to report their PA 3 months prior to 36 weeks of GA. Fetuses that were affected by both types of exercise (continuous and non-continuous) of leisure time physical activity during a 3-month period showed 
significantly higher HRV. This can be associated with a lower incidence of adverse outcomes in the fetus and neonate. ${ }^{62}$

An interventional study by Winn $e t a l^{63}$ consisted of 12 pregnant women whose gestational ages ranged between 26 and 36 weeks. In this study, real-time ultrasound was used to measure fetal breathing and fetal body movement during exercise. The intervention consisted of walking on a treadmill until the maternal HR reached $75 \%$ of the age-predicted maximal HR. Prior to their pregnancy, the participants in this study were mainly highly active. Winn and his colleagues ascertained that, following a treadmill run by the mother in the third trimester, fetal body movement and fetal breathing decreased after maternal exercise. Likewise, fetal body movement was shown to be affected by maternal exercise. ${ }^{64}$ In other studies, a significantly lower incidence of fetal body movement was observed in the first $5 \mathrm{~min}$ after maternal exercise and a significant decrease in fetal breathing occurred. ${ }^{6465}$ All studies investigated the effects of exercise on fetal cardiovascular activity in late gestation. The decrease in fetal body movement and fetal breathing may be associated with a transient distress for the fetus. Such distress is to be avoided during late gestation.

All in all, low/moderate-intensity PA does not appear to have any adverse effects on fetal ANS and might even have beneficial effects on fetal parasympathetic activity. However, resistance exercises in the supine position should be avoided since harm cannot be ruled out.

Moreover, the exercise intensity was shown to modulate fHR significantly. Cycling at a strenuous level during the third trimester showed an increase in mean fHR during exercise ${ }^{66}$ whereas cycling at a moderate level showed no significant effects in fHR. ${ }^{67} 68$ This is in line with a recently published review that reported a greater increase in $\mathrm{fHR}$ in relation to an exercise duration greater than $20 \mathrm{~min}$ in the third trimester only. ${ }^{69}$ In the majority of the studies, the fetal responses to cycling with an increase of $\mathrm{fHR}^{6470} 71$ and a transient reduction after the session were followed by a delayed increase during the recovery period. ${ }^{66} 7172$ In a further study, the fHR increased slightly following maternal exercise but did not reach clinical implication. ${ }^{73}$ The increase in fHR appeared to be higher during the third trimester than in the second trimester due to an increase in fetal activity. The transient reduction after the session can be interpreted as a physiological response of the fetus. This reduction can be due to a diminished arterial blood flow and reduced uterine blood flow immediately after the exercise. This can lead to a reduced fetal oxygen tension. The increase in fHR during the recovery period may therefore be accounted for by a compensatory mechanism of the fetus and should not be a cause for concern. The results made allowance for a significant increase in mean fHR during the first 5 min after exercise in comparison to the resting control condition. This is indicative of a transient stress phase for the fetus during exercise. However, this effect may be moderated by the rising maternal body temperature during such exercises ${ }^{745}$ (for more detail, see Ravanelli $\left.e t a l^{76}\right)$.

In sum, cycling at a strenuous level for more than $20 \mathrm{~min}$ in the third trimester should be avoided since it can lead to an increase in fHR. Although this may be indicative of a transient fetal distress, more research is still required to verify this theory.

\section{Cardiovascular activity-elite athletes}

Only minor changes in fHR were reported with regard to the fetal cardiovascular activity in elite athletes. Aerobic exercise, endurance exercise and resistance exercise were part of the regular training programme. Szymanski et $a l^{77}$ used umbilical artery Doppler indices, fetal heart tracing and BPP before and after exercise to investigate the effect of different extents of exercise on fHR. They divided the women in three groups according to their PA level (non-exerciser, regularly active, highly active). Like moderately active women, the post-exercise fHR in the highly active women was transiently lower than in the control group and was described as "transient FHR decelerations' ${ }^{77}$ p.5]. Due to their very short duration, these decelerations are not defined as bradycardia, as was the case in the previously described studies.

In sum, evidence suggests that maternal exercise can have a beneficial effect on the fetal ANS. Aerobic and walking all resulted in a transient increase in fHR, while swimming showed an increase in variability. The data do not clearly indicate whether these increases are induced by maternal exercise, rising maternal body temperature or by other factors such as fetal activity states. ${ }^{51}$

\section{EFFECTS OF PA ON FETAL INTRAUTERINE ENVIRONMENT}

The intrauterine environment, which maintains fetal oxygenation and substrate delivery, is a major factor in fetal development. ${ }^{78}$ The parameters described in most of the studies are summarised in table 5 .

With regard to the systolic/diastolic ratio (S/D ratio) - a standard method for measuring the function of the umbilical cord artery $^{79}$ - a number of research results confirm that exercise increases the umbilical blood flow and improves placental circulation. ${ }^{68} 80$ Moreover, the $\mathrm{S} / \mathrm{D}$ ratio is higher after cycling than after swimming, whereas the intensity between the act of cycling and of swimming did not differ. ${ }^{74}$ Exercise, but not moderateintensity walking, ${ }^{75}$ appears to enhance the placental circulation and is associated with the placental perfusion and transfer functions in active pregnant women. ${ }^{81}$ With regard to the amniotic fluid index, converging data suggest that aquatic exercises also caused this index to increase significantly. ${ }^{82}$ The amniotic fluid is highly supportive of the fetal development by virtue of the fact that it circulates from the mother to the fetus via the placenta. ${ }^{83}$ An increase in the amniotic fluid index may be a predictor for improved fetal sustenance ${ }^{84}$ which, in turn, might improve fetal development. More research is needed before any conclusions can be drawn from in this regard. 
Table 5 Overview of fetal parameters associated with intrauterine environment

\begin{tabular}{|c|c|c|c|c|}
\hline Method & Parameters & Description & Over the course of pregnancy & Interpretation \\
\hline \multirow[t]{2}{*}{$\begin{array}{l}\text { Doppler, } \\
\text { BPP }\end{array}$} & $\begin{array}{l}\text { Uteroplacental } \\
\text { blood flow and } \\
\text { umbilical blood flow }\end{array}$ & $\begin{array}{l}\text { Blood circulation between uterus, } \\
\text { placenta and the fetus }\end{array}$ & $\begin{array}{l}\text { Begins to increase from } \\
12 \text { GA until term. }{ }^{126} \text { The } \\
\text { umbilical artery oxygen } \\
\text { saturation, oxygen partial } \\
\text { pressure and pH decrease } \\
\text { and partial pressure of } \\
\text { carbon dioxide increase } \\
128\end{array}$ & $\begin{array}{l}\text { Associated with a well-functioning } \\
\text { maternal-fetal circulation and } \\
\text { placental perfusion }{ }^{126129}\end{array}$ \\
\hline & $\begin{array}{l}\text { Fetoplacental } \\
\text { growth and blood } \\
\text { flow }\end{array}$ & $\begin{array}{l}\text { The directions of blood flow from } \\
\text { mother to the placenta and the } \\
\text { blood flow from the placenta to } \\
\text { the fetus based on mean blood } \\
\text { velocity and the cross-sectional } \\
\text { area of the vessel. }{ }^{125} \text { The normal } \\
\text { range is: } 18.581 .4 \mathrm{~mL} / 100 \mathrm{~g} \text { fetal } \\
\text { weight }\end{array}$ & Increases over pregnancy ${ }^{127}$ & $\begin{array}{l}\text { Associated with a well-functioning } \\
\text { maternal-fetal circulation and } \\
\text { placental perfusion }{ }^{129}\end{array}$ \\
\hline
\end{tabular}

BPP, biophysical profile; GA, gestational age.

Clapp et $a l^{36}$ observed that a moderate-intensity, resistance exercise regimen in early pregnancy is associated with a significant increase in fetoplacental growth. This study included women who exercised on a regular basis. The authors observed that a significantly slow fetoplacental growth rate improved in these women as the amount of exercise increased in late pregnancy compared with other women who did not engage in any recreational weight-bearing exercise. Clapp et al also showed that moderate weight-bearing exercise enhances fetoplacental growth in early pregnancy ${ }^{36}$ and reduces fetoplacental growth in mid and late pregnancy. In a follow-up study, ${ }^{85}$ the group reported that a reduction in exercise volume in mid and late pregnancy enhances fetoplacental growth. This suggests that an increase in the extent of exercise in late pregnancy is associated with adverse effects in the fetus since it affects fetoplacental growth. A recent study ${ }^{86}$ reported an association between reduced placental weights and increased likelihoods of fetal growth restriction. This can be seen as an adaptive response to the reduction in the blood flow.

In sum, weight-bearing exercise in late pregnancy should be avoided, or at least reduced, due to adverse effects in fetoplacental growth rates. With respect to the umbilical cord artery, there is evidence that, regardless of intensity, the type of exercise performed affects the fetus in different ways and more research is therefore necessary before further recommendations can be made.

The weight of the placenta is taken as a measure of the functional capacity of the placenta. ${ }^{83} \mathrm{~A}$ number of studies suggest that there is a correlation between the weight of the placenta and perinatal outcome. A higher placenta weight (above the 90th percentile) is associated with, for example, a poor perinatal outcome or a low Apgar score, whereas a lower placenta weight (placenta weight is too low: below the 10 th percentile) ${ }^{87}$ is associated with medical complications for the mother. ${ }^{88}$ One study $^{81}$ reported a significant effect of maternal exercise on placental mass per kilogram of birth weight and a higher percentage of parenchymal tissue and villous vessel diameters for women who exercised than for those in the control group. This indicates that fetal-protective mechanisms help to maintain fetal substrate availability. ${ }^{81}$ A randomised controlled trial ${ }^{89}$ was carried out to determine the effects of regular exercise on placenta weight. HR monitors were used during the exercise session to supervise exercise intensity. Women in the experimental group trained 3 days per week from 9 weeks until 38-39 weeks of GA. No effects of maternal exercise on the placenta weight were reported.

Notably, these two studies were based on different types of PA. External factors, such as dietary intake, maternal life stress or placenta weight of previous deliveries, all which can influence the placenta weight, ${ }^{90}$ were not taken into consideration.

All in all, a high exercise volume in late pregnancy can decrease the umbilical blood flow. In addition, since the data suggest that the maternal prepregnancy level of exercise might influence the effects of exercise on placenta weight this should also be taken into account. On the basis of the current data, high exercise volume in late gestation cannot be recommended since a decrease 
of umbilical blood flow is associated with irregularities in maternal-fetal circulation.

\section{Effects on intrauterine environment-elite athletes}

Current evidence suggests that exercising above $90 \%$ of maximum maternal HR, even in highly active women, is not beneficial to the fetus.$^{7791}$ The elite athletes in the latter study by Salvesen $e t$ al included training sports such as biathlon, long distance running and race walking. Athletes had exercised 15-22 hours/week before pregnancy. The uteroplacental blood flow was investigated before, during and after the treadmill run. ${ }^{91}$ As reported by Salvesen $e t a l,{ }^{91}$ the mean uterine artery volume blood flow was reduced by $25 \%-60 \%$ during intensive exercise. Szymanski $e t a l^{77}$ reported that the fetuses of highly active women had lower HRs post-exercise. Minor alterations in umbilical cord blood and uterine artery were observed only immediately after the treadmill run. This reduction in $\mathrm{fHR}$ after the exercise is associated with a reduction in uterine blood flow. A reduction in uterine blood flow is associated with adverse effects for the fetus due to irregularities in the maternal-placenta-fetal circulation.

In sum, strenuous exercise above $90 \%$ of maximum maternal HR also induces a simultaneous reduction in uterine volume blood flow which, in turn, is in line with results from an earlier study where no changes were reported in placental blood flow pre-exercise and postexercise to a submaximal level. ${ }^{92}$ What is more, these data point to similar effects in elite athletes with regard to the intensity level. This should not be above $90 \%$ of VO2 max since it could induce fetal bradycardia and a reduction in uterine blood flow.

\section{MOVING FORWARD: PRENATAL RELAXATION TECHNIQUES AND THEIR EFFECTS ON THE FETAL AUTONOMIC NERVOUS SYSTEM}

Relaxation techniques are highly recommended during pregnancy. Mental-based techniques focus on active or passive relaxation by music or a guided imagery (GI). Body-based relaxation techniques include yoga, progressive muscle relaxation (PMR).

This section differentiates between physiological relaxation strategies such as yoga and psychological relaxation strategies like a GI or music during pregnancy.

\section{Yoga in pregnancy}

Only one study with a high number of participants $(n=335)$ reported a significant decrease of preterm labour and complications such as intrauterine growth restriction. The control group did not practice yoga but walked half an hour twice daily. ${ }^{93}$ The experimental group was required to perform yoga 1 hour daily from their enrolment in the study up until delivery. Yoga included physical postures (asanas) and meditation, commencing in the second trimester. A lower rate of pregnancyinduced hypertension and significantly higher birth weights than the control group were reported. Although these effects are positive, more research is still needed. Only one study distinguished between those women who were familiar with yoga and those who were not. Besides noting fetal/maternal parameters 24 hours after a single one-to-one yoga session, they questioned the women about fetal movement, contractions, leakage of fluid..$^{94}$ This study used a single session of yoga postures to determine possible effects on the fetus. In 25 women, divided into three groups, maternal blood pressure, maternal HR, uterine tocometry and fHR were recorded continuously. This study reported no significant effects of yoga in fetal parameters. This is in line with the randomised controlled study in which acute changes in fetal responses to yoga exercises were investigated. After a supervised one-off yoga session, no significant changes in fetal cardiovascular activity and umbilical artery blood flow were reported. ${ }^{95}$

Yoga can therefore be practised as a relaxation technique by women with low-risk pregnancies from the beginning or during their pregnancy.

\section{Music for prenatal relaxation}

It is not yet clear whether a GI or music also has benefits for the fetus. Recent studies have shown that music can help pregnant women to relax. ${ }^{96-99}$ Listening to music can also lead to fetal effects such as an increase in fetal movements and a decrease in uterine contractions. ${ }^{100} 101$ An increase in fetal movement may be associated with fetal well-being. ${ }^{41}$ In sum, music can be highly recommended for prenatal relaxation since it also leads to maternal relaxation.

\section{Guided imagery for prenatal relaxation}

GI belongs to the active relaxation techniques and might be an alternative method for relaxation. Listening to a GI for $18 \mathrm{~min}$ in the last trimester can lead to a decline in fetal motor activity and a significant increase in fHRV. ${ }^{102}$ An increase in fHR variability is associated with the ability to adapt to changing circumstances. In this study, we investigated the effects of an $18 \mathrm{~min}$ GI followed by an $18 \mathrm{~min}$ recovery period. A significant decrease in maternal cortisol level as well as lower umbilical and uterine activity resistance was reported.

Chuang $e a^{103}$ used a relaxation audio programme in healthy women who had been diagnosed as being at risk for preterm labour. The subjects listened to the audio programme every day via earphones. Survival analysis demonstrated that the experimental group had a significantly lower proportion of extreme preterm birth and that fewer were admitted to a neonatal intensive care unit. However, no effects on fetal development were reported.

By comparing different relaxation techniques, a study by Fink et $a l^{104}$ focused on two main relaxation strategies in the experimental group: PMR and GI. Fetal monitoring was performed with CTG, and fHR, fHR variation, acceleration and fetal body movement were extracted. In general, the authors found the main differences between the intervention and control group (quiet sitting). These included increased fHR long-term variation, decreased fHR short-term variation and decreased fHR acceleration. 
In addition, the authors reported higher uterine activity during PMR than in other conditions. Overall, however, the direction of the changes did not enable them to make any conclusive statements about a beneficial or adverse effect. However, increased uterine activity during PMR may limit this intervention, particularly in pregnant woman with increased risk of preterm contractions.

In sum, mental/body-based relaxation programme might have a beneficial impact on fetal development. In mental-based relaxation programme, music can lead to a significant increase in fetal movements, while GI can decrease maternal cortisol levels which, in turn, might reduce negative influences on the fetus. With regard to body-based relaxation programme, only the PMR programme increased uterine activity. While it is difficult to conclude any effects on the fetus on the basis of a relatively small number of studies, the data point to a mainly positive impact on the mother that can then lead to positive effects on the fetus. Further studies are required to identify these effects.

\section{CONCLUSION AND FUTURE DIRECTIONS}

In this review, we show that the current evidence with regard to PA and fetal development is still wanting. This work put forward the discussion about PA in pregnancy by critically summarising the effects on fetal development. Notably, only healthy women were included in this scoping review. However, different study designs and approaches were used in the various studies. In addition, it is a limiting factor that some studies used nonsupervised exercises and investigated exercise level based on self-reports. Maternal nutrition and body composition during pregnancy should also be investigated since the maternal metabolic system determines stress perception, physical working capacity and fetal development. ${ }^{105} 106$

On the basis of previous studies, this review showed that maximal exertion (training intensity above $90 \%$ of VO2 max) may lead to fetal bradycardia, regardless of the women's earlier level of activity. Furthermore, it remains unclear as to whether resistance exercise in the supine position can have adverse effects on the fetus and perhaps even cause obstetric contraindications. Furthermore, maternal exercise can lead to a transient increase of fHR after exercise, potentially causing temporary distress to the fetus. However, some studies ${ }^{67} 71107108$ found a transitional bradycardia or tachycardia ${ }^{43}$ as a result of maternal exercise which may be caused by maternal body movement. ${ }^{108} 109 \mathrm{fHRV}$ was also shown to be dependent on the fetal activity state and the gestational age. ${ }^{51}$

Maternal exercise also showed beneficial effects for the fetus. Low-intensity exercise in early pregnancy increases the umbilical blood flow and can improve placental circulation as well as the fetal cardiac adaptation to the environment. Relaxation techniques did not show any adverse or beneficial effects for the fetus. More interventional research is necessary to determine whether relaxation techniques can pass on and augment the possible positive effects for the mother to the fetus. In conclusion, low-intensity exercise is not liable to pose any serious risk to the fetus.

In future, PAs will have to be well defined and supervised to avoid any bias. However, changes in fetal development in response to maternal PA during the whole pregnancy from early pregnancy until delivery combined with prepregnancy parameters have not yet been reported. For future studies, it would be helpful to include the maternal prepregnancy body mass index (BMI) and maternal gestational weight gain since these can have an impact on fetal cardiac activity and infants risk of obesity. ${ }^{110-112}$ The maternal prepregnancy BMI is also associated with a higher risk of gestational diabetes mellitus. ${ }^{113}$ This diagnosis of gestational diabetes mellitus can lead to a higher maternal psychological stress during pregnancy which is associated with an altered stress reactivity in the newborn. ${ }^{114}$

Investigating the maternal prepregnancy activity status might enable us to adjust the duration and intensity of exercises so as to measure different extents of exercise, for example, mild, moderate or intensive exercise. As reported in different studies, the intensity might play a role for the fetus, and studies with pregnant athletes are rare, making it difficult to create a consistent and complete picture. Finally, there is still a lack of research with structured study designs containing prepregnancy parameters. This is necessary if we are to fully understand the complexity of fetal programming and to determine appropriately whether PA is a beneficial recommendation for both mother and fetus.

\section{Author affiliations}

${ }^{1}$ Institute for Diabetes Research and Metabolic Diseases (IDM) of the Helmholtz Center Munich at the University of Tübingen/fMEG Center, Tübingen, Germany ${ }^{2}$ German Center for Diabetes Research (DZD e.V.), University of Tübingen, Tübingen, Germany

${ }^{3}$ Department of Internal Medicine IV, Division of Endocrinology, Diabetology, and Nephrology, University Hospital Tübingen, Tübingen, Germany

${ }^{4}$ Institute of Medical Psychology and Behavioral Neurobiology, Eberhard Karls University Tübingen, Tübingen, Germany

${ }^{5}$ Department of Obstetrics and Gynaecology, University of Tübingen, Tübingen, Germany

${ }^{6}$ Department of Pharmacy and Biochemistry, Institute of Pharmaceutical Sciences; Interfaculty Centre for Pharmacogenomics and Pharma Research, Eberhard Karls University Tübingen, Tübingen, Germany

\section{Twitter llena Bauer @Bauerllena}

Acknowledgements We acknowledge support by Deutsche Forschungsgemeinschaft and Open Access Publishing Fund of University of Tübingen.

Contributors IB did the search for literature, interpreted the literature and wrote the manuscript. JH, SK and IB conceptualised the work and revised it critically. $\mathrm{JP}-\mathrm{F}, \mathrm{FS}, \mathrm{MH}, \mathrm{AF}$ and $\mathrm{HP}$ revised the manuscript critically for important intellectual content. All authors read and approved the final version of the manuscript.

Funding This work was partially funded by the German Center of Diabetes Research (DZD e.V), Tübingen, Germany and the Centre for Integrative

Neuroscience (CIN), Tübingen, Germany (Mini Research Training Group, CIN/EXC 307).

Competing interests None declared.

Patient consent for publication Not required.

Provenance and peer review Not commissioned; externally peer reviewed. 
Data availability statement There are no data in this work.

Open access This is an open access article distributed in accordance with the Creative Commons Attribution Non Commercial (CC BY-NC 4.0) license, which permits others to distribute, remix, adapt, build upon this work non-commercially, and license their derivative works on different terms, provided the original work is properly cited, appropriate credit is given, any changes made indicated, and the use is non-commercial. See: http://creativecommons.org/licenses/by-nc/4.0/.

\section{ORCID iDs}

Ilena Bauer http://orcid.org/0000-0002-6561-4121

Julia Hartkopf http://orcid.org/0000-0001-6069-4655

Franziska Schleger http://orcid.org/0000-0003-2476-4147

Manfred Hallschmid http://orcid.org/0000-0002-0352-1106

Jan Pauluschke-Fröhlich http://orcid.org/0000-0002-2953-3682

Hubert Preissl http://orcid.org/0000-0002-8859-4661

\section{REFERENCES}

1 Barakat R, Perales M, Garatachea N, et al. Exercise during pregnancy. A narrative review asking: what do we know? $\mathrm{Br} J$ Sports Med 2015;49:1377-81.

2 Korsten-Reck U, Marquardt K, Wurster KG. Schwangerschaft und Sport: pregnancy and sports. Deutsche Zeitschrift für Sportmedizin 2009;60:117-21.

3 Newton ER, May L. Adaptation of Maternal-Fetal physiology to exercise in pregnancy: the basis of guidelines for physical activity in pregnancy. Clinical Medicine Insights: Women's Health 2017;10:1179562X1769322-12.

4 Teixeira C, Figueiredo B, Conde A, et al. Anxiety and depression during pregnancy in women and men. J Affect Disord 2009;119:142-8.

5 Evenson KR, Moos M-K, Carrier K, et al. Perceived barriers to physical activity among pregnant women. Matern Child Health $\mathrm{J}$ 2009;13:364-75.

6 The American College of obstetricians and Gynecologists. physical activity and exercise during pregnancy and the postpartum period: Committee opinion. Committee opinion 2002, reaffirmed, 2017. Available: www.acog.org [Accessed 19 Aug 2019].

7 Mottola MF, Davenport MH, Ruchat SM, et al. Canadian guideline for physical activity throughout pregnancy. $\mathrm{Br} J$ Sports Med 2019;2018:1339-46

8 UK CMO Guidelines Writing Group. Uk chief medical officers' physical activity guidelines. Gov.uk 2019;34 www.gov.uk/dhsc

9 The American College of Obstetricians and Gynecologists. FAQ119 exercise during pregnancy, 2017. Available: https://www.acog.org/ Patients/FAQs/Exercise-During-Pregnancy

10 World Health Organization. Obesity and overweight, 2018. Available: www.who.int [Accessed 9 Nov 2018].

11 Parker HW, Tovar A, McCurdy K, et al. Associations between prepregnancy $\mathrm{BMI}$, gestational weight gain, and prenatal diet quality in a national sample. PLoS One 2019;14:e0224034.

12 Leddy MA, Power ML, Schulkin J. The impact of maternal obesity on maternal and fetal health. Rev Obstet Gynecol 2008;1:170-8.

13 LifeCycle Project - Maternal Obesity and Childhood Outcomes Study Group. Association of gestational weight gain with adverse maternal and infant outcomes. JAMA 2019;17:1702-15.

14 Davenport MH, Sobierajski F, Mottola MF, et al. Glucose responses to acute and chronic exercise during pregnancy: a systematic review and meta-analysis. Br J Sports Med 2018;52:1357-66.

15 Connolly CP, Conger SA, Montoye AHK, et al. Walking for health during pregnancy: a literature review and considerations for future research. J Sport Health Sci 2019;8:401-11.

16 Dietz P, Watson ED, Sattler MC, et al. The influence of physical activity during pregnancy on maternal, fetal or infant heart rate variability: a systematic review. BMC Pregnancy Childbirth 2016;16:326.

17 Gregg VH, Ferguson JE. Exercise in pregnancy. Clin Sports Med 2017;36:741-52.

18 Harrison CL, Brown WJ, Hayman M, et al. The role of physical activity in preconception, pregnancy and postpartum health. Semin Reprod Med 2016;34:28-37.

19 Aune D, Schlesinger S, Henriksen T, et al. Physical activity and the risk of preterm birth: a systematic review and meta-analysis of epidemiological studies. BJOG: Int J Obstet Gy 2017;124:1816-26.

20 Davenport MH, McCurdy AP, Mottola MF, et al. Impact of prenatal exercise on both prenatal and postnatal anxiety and depressive symptoms: a systematic review and meta-analysis. $\mathrm{Br} J$ Sports Med 2018;52:1376-85.
21 Barker DJP. The fetal and infant origins of adult disease: the womb may be more important than the home. BMJ 1990;301.

22 Kwon EJ, Kim YJ. What is fetal programming?: a lifetime health is under the control of in utero health. Obstet Gynecol Sci 2017;60:506-19.

23 Hanson MA, Gluckman PD. Early developmental conditioning of later health and disease: physiology or pathophysiology? Physiol Rev 2014;94:1027-76.

24 Everett TR, Peebles DM. Antenatal tests of fetal wellbeing. Semin Fetal Neonatal Med 2015;20:138-43.

25 Grivell RM, Alfirevic Z, Gyte GML, et al. Antenatal cardiotocography for fetal assessment (review). Cochrane Database of Systematic Reviews 2015;9.

26 Alfirevic Z, Gyte GML, Cuthbert A, et al. Continuous cardiotocography (CTG) as a form of electronic fetal monitoring (EFM) for fetal assessment during labour (review). Cochrane Database of Systematic Reviews 2017;2.

27 Nagar T, Sharma D, Choudhary M, et al. The role of uterine and umbilical artery Doppler in high-risk pregnancy: a prospective observational study from India.. Clinical Medicine Insights: Reproductive Health 2015;9.

28 Manning FA, Profile FB. Fetal biophysical profile. Obstet Gynecol Clin North Am 1999;26:557-77.

29 Lalor JG, Fawole B, Alfirevic Z, et al. Biophysical profile for fetal assessment in high risk pregnancies. Cochrane Database Syst Rev 2008;102:CD000038.

30 Committee CS. ISUOG practice guidelines: use of Doppler ultrasonography in obstetrics. Ultrasound Obstet Gynecol 2013;41:233-9.

31 MacDonald TM, Hui L, Robinson AJ, et al. Cerebral-placentaluterine ratio as novel predictor of late fetal growth restriction: prospective cohort study. Ultrasound Obstet Gynecol 2019;54:367-75.

32 Gustafson KM, Allen JJB, Yeh H-Wen, et al. Characterization of the fetal diaphragmatic magnetomyogram and the effect of breathing movements on cardiac metrics of rate and variability. Early Hum Dev 2011:87:467-75

33 Anderson AL, Thomason ME. Functional plasticity before the cradle: a review of neural functional imaging in the human fetus. Neurosci Biobehav Rev 2013;37:2220-32.

34 May LE, Allen JJB, Gustafson KM. Fetal and maternal cardiac responses to physical activity and exercise during pregnancy. Early Hum Dev 2016;94:49-52.

35 Sussman D, Lye SJ, Wells GD. Impact of maternal physical activity on fetal breathing and body movement--A review. Early Hum Dev 2016;94:53-6.

36 Clapp JF, Kim H, Burciu B, et al. Beginning regular exercise in early pregnancy: effect on fetoplacental growth. Am J Obstet Gynecol 2000;183:1484-8

37 Di Mascio D, Magro-Malosso ER, Saccone G, et al. Exercise during pregnancy in normal-weight women and risk of preterm birth: a systematic review and meta-analysis of randomized controlled trials. Am J Obstet Gynecol 2016;215:561-71.

38 Davenport MH, Meah VL, Ruchat S-M, et al. Impact of prenatal exercise on neonatal and childhood outcomes: a systematic review and meta-analysis. Br J Sports Med 2018;52:1386-96.

39 Sigurdardottir T, Steingrimsdottir T, Geirsson RT, et al. Do female elite athletes experience more complicated childbirth than nonathletes? A case-control study. Br J Sports Med 2019;53:354-8.

40 Wilds PL. Observations of intrauterine fetal breathing movements-A review. Am J Obstet Gynecol 1978;131:315-38.

41 Neldam S. Fetal movements as an indicator of fetal well-being. Dan Med Bull 1986;33:213-21.

42 Brändle J, Preissl H, Draganova R, et al. Heart rate variability parameters and fetal movement complement fetal behavioral states detection via magnetography to monitor neurovegetative development. Front Hum Neurosci 2015;9:147.

43 Schuster HP THJ. EKG-Kurs für Isabel. 7th edn. Stuttgart: Georg Thieme Verlag, 2017.

44 Vanderlei LCM, Pastre CM, Hoshi RA, et al. Basic notions of heart rate variability and its clinical applicability. Rev Bras Cir Cardiovasc 2009:24:205-17.

45 Acharya UR, Joseph KP, Kannathal N, et al. Heart rate variability: a review. J Med Biol Eng 2006;44:1031-51.

46 May LE, Knowlton J, Hanson J, et al. Effects of exercise during pregnancy on maternal heart rate and heart rate variability. $P M \& R$ 2016;8:611-7.

47 Carter JB, Banister EW, Blaber AP. Effect of endurance exercise on autonomic control of heart rate. Sports Medicine 2003;33:33-46. 
48 Malik M CAJ. Components of Heart Rate Variability - What They Really Mean and What We Really Measure. Am J Cardiol 1990:821-2.

49 Virtanen R, Jula A, Kuusela T, et al. Reduced heart rate variability in hypertension: associations with lifestyle factors and plasma renin activity. J Hum Hypertens 2003;17:171-9.

50 Carmichael L, Campbell K, Patrick J. Fetal breathing, gross fetal body movements, and maternal and fetal heart rates before spontaneous labor at term. Am J Obstet Gynecol 1984;148:675-9.

51 May LE, Glaros A, Yeh H-W, et al. Aerobic exercise during pregnancy influences fetal cardiac autonomic control of heart rate and heart rate variability. Early Hum Dev 2010;86:213-7.

52 Hof JT, Nijhuis IJM, Mulder EJH, et al. Longitudinal study of fetal body movements: nomograms, intrafetal consistency, and relationship with episodes of heart rate patterns A and B. Pediatr Res 2002;52:568-75.

53 Gustafson KM, May LE, Yeh H-wen, et al. Fetal cardiac autonomic control during breathing and non-breathing epochs: the effect of maternal exercise. Early Hum Dev 2012;88:539-46.

54 Bgeginski R, Almada BP, Kruel LFM. Fetal heart rate responses during maternal resistance exercise: a pilot study. Rev. Bras. Ginecol. Obstet. 2015;37:133-9.

55 Avery ND, Stocking KD, Tranmer JE, et al. Fetal responses to maternal strength conditioning exercises in late gestation. Can J Appl Physiol 1999;24:362-76.

56 Green RC, Schneider K, MacLENNAN AH. The fetal heart response to static antenatal exercises in the supine position. Australian Journal of Physiotherapy 1988;34:3-7.

57 Mottola MF, Nagpal TS, Bgeginski R, et al. Is supine exercise associated with adverse maternal and fetal outcomes? A systematic review. Br J Sports Med.

58 Silveira C, Pereira BG, Cecatti JG, et al. Fetal cardiotocography before and after water aerobics during pregnancy. Reprod Health 2010;7:23.

59 McMurray R, Katz V, Poe M, et al. Maternal and fetal responses to low-impact aerobic dance. Am J Perinatol 1995;12:282-5.

60 Melo ASO, Silva JLPE, Melo FdeO, et al. Is moderate intensity exercise during pregnancy safe for the fetus? an open clinical trial. Rev Bras Ginecol Obstet 2019;41:531-8.

61 May LE, Suminski RR, Berry A, et al. Maternal physical activity mode and fetal heart outcome. Early Hum Dev 2014;90:365-9.

62 Sampson MB, Mudaliar NA, Lele AS. Fetal heart rate variability as an indicator of fetal status. Postgrad Med 1980;67:213-5.

63 Winn H, Hess O, Goldstein I, et al. Fetal responses to maternal exercise: effect on fetal breathing and body movement. Am J Perinatol 1994;11:263-6.

64 Manders MAM, Sonder GJB, Mulder EJH, et al. The effects of maternal exercise on fetal heart rate and movement patterns. Early Hum Dev 1997;48:237-47.

65 Hatoum N, Clapp JF, Newman MR, et al. Effects of maternal exercise on fetal activity in late gestation. $J$ Matern Fetal Med 1997;6:134-9.

66 Brenner IKM, Wolfe LA, Monga M, et al. Physical conditioning effects on fetal heart rate responses to graded maternal exercise. Medicine \& Science in Sports \& Exercise 1999;31:792-9.

67 Spinnewijn WEM, Lotgering FK, Struijk PC, et al. Fetal heart rate and uterine contractility during maternal exercise at term. Am J Obstet Gynecol 1996;174:43-8.

68 Katz VL, McMurray R, Berry MJ, et al. Fetal and uterine responses to immersion and exercise. American College of Obstetrics and Gynecology 1988;72:225-30.

69 Skow RJ, Davenport MH, Mottola MF, et al. Effects of prenatal exercise on fetal heart rate, umbilical and uterine blood flow: a systematic review and meta-analysis. Br J Sports Med 2019;53:124-33.

70 MacPhail A, Davies GA, Victory R, et al. Maximal exercise testing in late gestation: fetal responses. Obstet Gynecol 2000;96:565-70.

71 Webb KA, Wolfe LA, McGrath MJ. Effects of acute and chronic maternal exercise on fetal heart rate. J Appl Physio 1994;77:2207-13.

72 van Doorn MB, Lotgering FK, Struijk PC, et al. Maternal and fetal cardiovascular responses to strenuous bicycle exercise. Am J Obstet Gynecol 1992;166:854-9.

73 Rafla NM, Cook JR. The effect of maternal exercise on fetal heart rate. J Obstet Gynaecol 1999;19:381-4

74 Watson WJ, Katz VL, Hackney AC, et al. Fetal responses to maximal swimming and cycling exercise during pregnancy. Obstet Gynecol 1991;77:382-6.

75 de Oliveria Melo AS, Silva JLP, Tavares JS, et al. Effect of a physical exercise program during pregnancy on Uteroplacental and fetal blood flow and fetal growth. Obstetrics \& Gynecology 2012;120:302-10.

76 Ravanelli N, Casasola W, English T, et al. Heat stress and fetal risk. environmental limits for exercise and passive heat stress during pregnancy: a systematic review with best evidence synthesis. $\mathrm{Br} \mathrm{J}$ Sports Med 2019;53:799-805.

77 Szymanski LM, Satin AJ. Strenuous exercise during pregnancy: is there a limit? Am J Obstet Gynecol 2012;207:179.e1-179.e6.

78 Nugent BM, Bale TL. The omniscient placenta: metabolic and epigenetic regulation of fetal programming. Front Neuroendocrinol 2015;39:28-37.

79 Anderson AL, Thomason ME. Functional plasticity before the cradle: a review of neural functional imaging in the human fetus. Neuroscience \& Biobehavioral Reviews 2013;37:2220-32.

80 Rafla NM, Beazely JM. The effect of maternal exercise on fetal umbilical artery waveforms. Eur J Obstet Gynecol Reprod Biol 1991;40:119-22.

81 Jackson MR, Gott P, Lye SJ, et al. The effects of maternal aerobic exercise on human placental development: placental volumetric composition and surface areas. Placenta 1995;16:179-91.

82 Sechrist DM, Tiongco CG, Whisner SM, et al. Physiological effects of aquatic exercise in pregnant women on bed rest. Occup Ther Health Care 2015;29:330-9.

83 Lindower JB. Water balance in the fetus and neonate. Semin Fetal Neonatal Med 2017;22:71-5

84 Moore TR, Cayle JE. The amniotic fluid index in normal human pregnancy. Am J Obstet Gynecol 1990;162:1168-73.

85 Clapp JF, Kim H, Burciu B, et al. Continuing regular exercise during pregnancy: effect of exercise volume on fetoplacental growth. $A m \mathrm{~J}$ Obstet Gynecol 2002;186:142-7.

86 Hong-Jiao L, Peng-Cheng L, Jing $\mathrm{H}$, et al. Placental weight and size in relation to fetal growth restriction: a case-control study. Journal of Maternal Fetal Neonatal Medicine 2019.

87 Janthanaphan M, Kor-Anantakul O, Geater A. Placental weight and its ratio to birth weight in normal pregnancy at Songkhlanagarind Hospital. J Med Assoc Thai 2006;89:130-7.

88 Barakat R, Stirling JR, Lucia A. Does exercise training during pregnancy affect gestational age? a randomised controlled trial. $\mathrm{Br}$ J Sports Med 2008;42:674-8.

89 Barakat R, Vargas M, Brik M, et al. Does exercise during pregnancy affect placental weight?: a randomized clinical trial. Eval Health Prof 2018:41:400-14.

90 Thornburg KL, O'Tierney PF, Louey S. Review: the placenta is a programming agent for cardiovascular disease. Placenta 2010;31 Suppl:54-9.

91 Salvesen Kjell Å, Hem E, Sundgot-Borgen J. Fetal wellbeing may be compromised during strenuous exercise among pregnant elite athletes. Br J Sports Med 2012;46:279-83.

92 Rauramo I, Forss M. Effect of exercise on maternal hemodynamics and placental blood flow in healthy women. Acta Obstet Gynecol Scand 1988;67:21-5.

93 Narendran S, Nagarathna R, Narendran V, et al. Efficacy of yoga on pregnancy outcome. J Altern Complement Med 2005;11:237-44.

94 Polis RL, Gussman D, Kuo Y-H. Yoga in pregnancy: an examination of maternal and fetal responses to 26 yoga postures. Obstet Gynecol 2015;126:1237-41.

95 Babbar S, Hill JB, Williams KB, et al. Acute feTal behavioral response to prenatal yoga: a single, blinded, randomized controlled trial (try yoga). Am J Obstet Gynecol 2016;214:399.e1-399.e8.

96 Wulff V, Hepp P, Fehm T, et al. Music in obstetrics: an intervention option to reduce tension, pain and stress. Geburtshilfe Frauenheilkd 2017;77:967-75.

97 Fink NS, Urech C, Cavelti M, et al. Relaxation during pregnancy: what are the benefits for mother, fetus, and the newborn? A systematic review of the literature. J Perinat Neonatal Nurs 2012;26:296-306.

98 Ventura T, Gomes MC, Carreira T. Cortisol and anxiety response to a relaxing intervention on pregnant women awaiting amniocentesis. Psychoneuroendocrinology 2012;37:148-56.

99 Nwebube C, Glover V, Stewart L. Prenatal listening to songs composed for pregnancy and symptoms of anxiety and depression: a pilot study. BMC Complement Altern Med 2017;17:256.

100 Gebuza G, Dombrowska A, Kaźmierczak M, et al. The effect of music therapy on the cardiac activity parameters of a fetus in a cardiotocographic examination. J Matern Fetal Neonatal Med 2017:30:2440-5.

101 García González J, Ventura Miranda MI, Manchon García F, et al. Effects of prenatal music stimulation on fetal cardiac state, newborn anthropometric measurements and vital signs of pregnant women: a randomized controlled trial. Complement Ther Clin Pract 2017;27:61-7. 
102 DiPietro JA, Costigan KA, Nelson P, et al. Fetal responses to induced maternal relaxation during pregnancy. Biol Psychol 2008;77:11-19.

103 Chuang L-L, Lin L-C, Cheng P-J, et al. The effectiveness of a relaxation training program for women with preterm labour on pregnancy outcomes: a controlled clinical trial. Int J Nurs Stud 2012;49:257-64.

104 Fink NS, Urech C, Isabel F, et al. Fetal response to abbreviated relaxation techniques. A randomized controlled study. Early Hum Dev 2011;87:121-7.

105 Hurley KM, Caulfield LE, Sacco LM, et al. Psychosocial influences in dietary patterns during pregnancy. J Am Diet Assoc 2005;105:963-6.

106 Fehlert E, Willmann K, Fritsche L, et al. Gestational diabetes alters the fetal heart rate variability during an oral glucose tolerance test: a fetal magnetocardiography study. BJOG 2017;124:1891-1898.

107 Kennelly MM, McCaffrey N, McLoughlin P, et al. Fetal heart rate response to strenuous maternal exercise: not a predictor of fetal distress. Am J Obstet Gynecol 2002;187:811-6.

108 Carpenter MW, Sady SP, Hoegsberg B, et al. Fetal heart rate response to maternal exertion. JAMA 1988;259:3006-9.

109 Paolone AM, Shangold M, Paul D, et al. Fetal heart rate measurement during maternal exercise--avoidance of artifact. Med Sci Sports Exerc 1987;19:605-9.

110 Josey MJ, McCullough LE, Hoyo C, et al. Overall gestational weight gain mediates the relationship between maternal and child obesity. BMC Public Health 2019;19:1062.

111 Voegtline KM, Costigan KA, Henderson JL, et al. Fetal heart rate and motor development in overweight and obese pregnant women. Int J Gynaecol Obstet 2016;133:103-7.

112 Mat Husin H, Schleger F, Bauer I, et al. Maternal weight, weight gain, and metabolism are associated with changes in fetal heart rate and variability. Obesity 2020;28:114-21.

113 Andersson-Hall UK, Järvinen EAJ, Bosaeus MH, et al. Maternal obesity and gestational diabetes mellitus affect body composition through infancy: the PONCH study. Pediatr Res 2019;85:369-77.

114 Nazzari S, Fearon P, Rice F, et al. Beyond the HPA-axis: exploring maternal prenatal influences on birth outcomes and stress reactivity. Psychoneuroendocrinology 2019;101:253-62.

115 Pildner von Steinburg S, Boulesteix A-L, Lederer C, et al. What is the "normal" fetal heart rate? PeerJ 2013;1:e82.
116 Van Leeuwen $\mathrm{P}$, Lange S, Bettermann $\mathrm{H}$, et al. Fetal heart rate variability and complexity in the course of pregnancy. Early Hum Dev 1999;54:259-69.

117 Rath W, Gembruch U, Schmidt S. Geburtshilfe und Perinatalmedizin: Pränataldiagnostik - Erkrankungen - Entbindung. 2nd edn. Stuttgart, New York: Thieme Verlag, 2010.

118 Van Leeuwen P, Cysarz D, Edelhäuser F, et al. Heart rate variability in the individual fetus. Auton Neurosci 2013;178:24-8.

119 Visser GHA, Goodman JDS, Levine DH, et al. Micturition and the heart period cycle in the human fetus. BJOG:An international journal of O\&G 1981;88:803-5.

120 Wheeler T, Roberts K, Peters J, et al. Detection of fetal movement using Doppler ultrasound. Obstet Gynecol 1987;70:251-4.

121 The American College of Obstetricians and Gynecologists. Intrapartum fetal heart rate monitoring: nomenclature, interpretation, and general management principles: ACOG practice Bulletin 2009;106.

122 Bravo-Valenzuela NJ, Rocha LA, Júnior EA. Fetal cardiac arrythmias: current evidence. Annals of Pediatric Cardiology 2018;11:332.

123 Copel JNU. Fetal bradycardia. Obstetrics and Gynecology, 2017. Available: https://www.cancertherapyadvisor.com/home/decisionsupport-in-medicine/obstetrics-and-gynecology/fetal-bradycardia/ [Accessed 9 Dec 2019].

124 Jakes AD, Whybrow R, Spencer C, et al. Reduced fetal movements. BMJ 2018;360:k570.

125 Wang Y. Vascular biology of the placenta. San Rafael (CA: Morgan \& Claypool Life Sciences, 2010: 2. 1-98.

126 Kliman HJ. Uteroplacental blood flow. The story of decidualization, menstruation, and trophoblast invasion. Am J Pathol 2000;157:1759-68.

127 Acharya G, Sonesson SE, Flo K, et al. Hemodynamic aspects of normal human feto-placental (umbilical) circulation. Acta Obstet Gynecol Scand 2016;95:672-82.

128 Nyberg MK, Johnsen SL, Rasmussen S, et al. Fetal breathing is associated with increased umbilical blood flow. Ultrasound Obstet Gynecol 2010;36:718-23.

129 Sutton MS, Theard MA, Bhatia SJ, et al. Changes in placental blood flow in the normal human fetus with gestational age. Pediatr Res 1990;28:383-7.

130 Naeye RL. Functionally important disorders of the placenta, umbilical cord, and fetal membranes. Human Pathology 1986;7:680-91. 